\title{
The equatorward wall of the subauroral trough in the afternoon/evening sector
}

\author{
G. W. Prölss \\ Argelander Institut für Astronomie, Universität Bonn, Auf dem Hügel 71, 53121 Bonn, Germany
}

Received: 23 October 2006 - Revised: 25 January 2007 - Accepted: 15 February 2007 - Published: 29 March 2007

\begin{abstract}
Although ionospheric troughs are a very important feature of the subauroral ionosphere, many of their properties remain incompletely documented and understood. Here Dynamics Explorer-2 satellite data are used to investigate one specific part of this complex phenomenon, namely its equatorward wall. We find that in the afternoon/evening sector of the Northern Hemisphere the location of this density drop depends primarily on the level of geomagnetic activity and magnetic local time. Longitudinal variations are only of secondary importance. A formula is derived which summarizes these variations. The magnitude of the density drop in the trough wall depends primarily on altitude and longitude, and to a lesser degree on local time and geomagnetic activity. These variations are also described quantitatively. Using a superposed epoch type of averaging procedure, a mean latitudinal profile of the trough wall is derived. No anomalous increase in the density at the equatorward edge of the trough is observed. There is, however, a significant increase in the electron temperature at the location of the density drop. Our results are important for the empirical description and numerical simulation of ionospheric troughs. They also may be used to define the boundary between middle and subauroral latitudes.
\end{abstract}

Keywords. Ionosphere (Ionosphere-magnetosphere interactions; Ionospheric disturbances; Plasma temperature and density)

\section{Introduction}

One of the most striking features of the subauroral ionosphere is a sudden drop in the ionization density; see Fig. 1. This density drop constitutes the equatorward wall of a phenomenon which has been designated as "main ionospheric

Correspondence to: G. W. Prölss

(gproelss@astro.uni-bonn.de) trough" (Muldrew, 1965) or "mid-latitude trough" (Sharp, 1966). The properties of this prominent anomaly have been investigated in numerous studies, and pertinent results are summarized in the review papers by Moffett and Quegan (1983) and Rodger et al. (1992). These papers also contain a discussion of the physics of this phenomenon. In spite of this effort, many properties of subauroral troughs remain incompletely documented and understood.

Recently, interest in this field has been revived by new data sets like the Cosmos-900 and Intercosmos-19 satellite measurements (e.g. Ben'kova et al., 1992; Besprozvannaya et al., 1995; Deminov et al., 1996a, b; Afonin et al., 1997; Annakuliev et al., 1997; Shestakova et al., 1998; Zikrach et al., 1999; Karpachev, 2003; and references therein) or the total electron content measurements based on the NNSS and GPS satellite systems (e.g. Mallis and Essex, 1993; Hargreaves and Burns, 1996; Horvath and Essex, 2003; Wielgosz et al., 2004; Afraimovich et al., 2005; and references therein). New analysis techniques like radiotomography have also contributed to the renewed interest in this field (e.g. Kersley et al., 1997; Aladjev et al., 2001; Namgaladze et al., 2003; Pryse et al., 1998, 2005; Meggs et al., 2005; Voiculescu et al., 2006; and references therein). Here we use Dynamics Explorer-2 satellite data to investigate one specific aspect of a subauroral trough, namely its equatorward wall. First, this density drop represents an important, arguably the most important, part of a trough. Second, this feature may be used to define a fundamental boundary in the ionosphere, namely the transition from middle to subauroral latitudes. Third, this wall may be identified with relative ease and parameterized with sufficient accuracy; these are advantages which should not be underestimated in this field.

The general format of our presentation resembles that of a recent investigation of the subauroral electron temperature enhancement (Prölss, 2006). First, data selection and processing are discussed (Sect. 2). Next, the location of the trough wall and its dependence on magnetic activity, local

Published by Copernicus GmbH on behalf of the European Geosciences Union. 


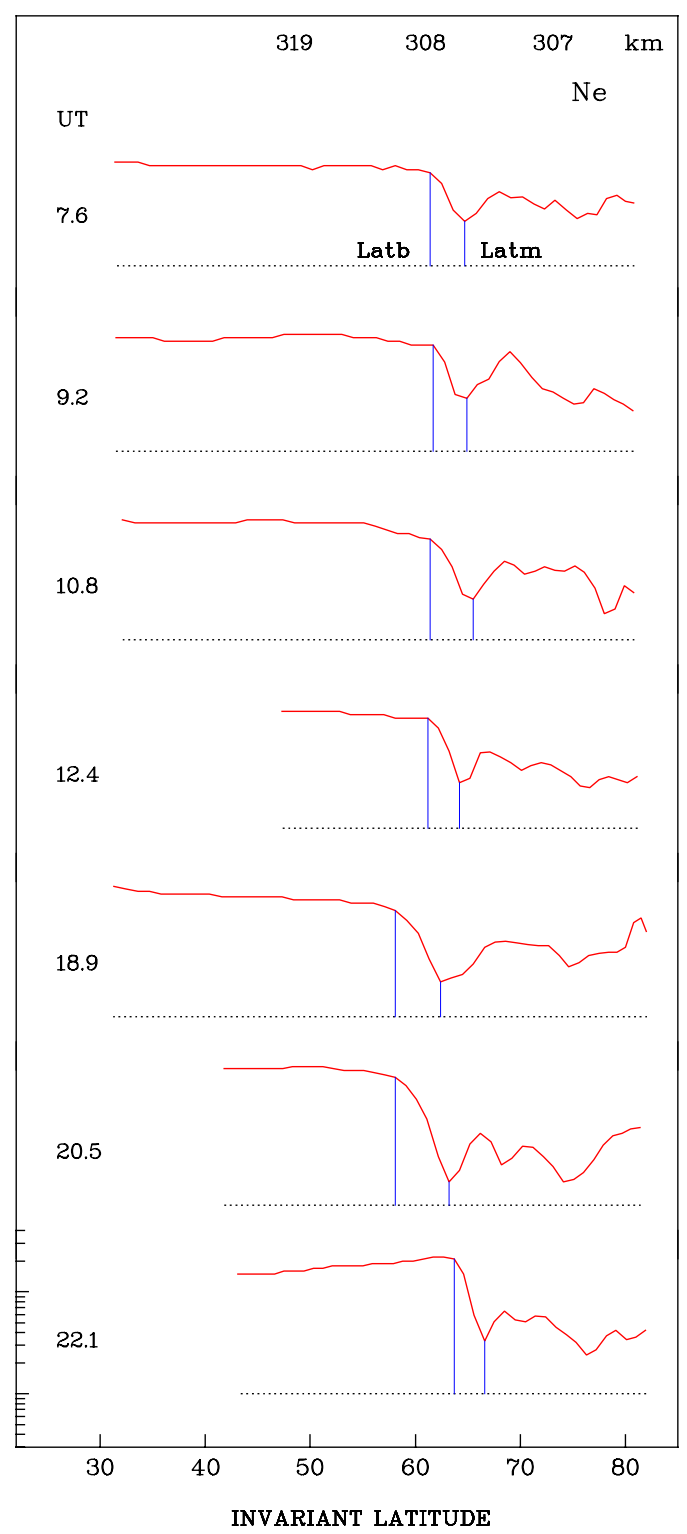

Fig. 1. Examples of relatively simple ionospheric trough structures. A sequence of seven latitudinal profiles of the electron density is shown, as obtained by the DE-2 satellite on 9 December 1981. The universal time of observation is indicated to the left of each profile. The density is plotted on a logarithmic scale, an example of which is shown in the bottom part of the figure. For each profile, a dotted line marks the $10^{11} \mathrm{~m}^{-3}$ density level. The data refer to the northern winter hemisphere, and at $60^{\circ}$ inv. latitude the solar zenith angle is larger than 105 degrees. Solar local time of observation was approximately 17:40 h, and the magnetic local time varied between about 17:00 and 19:00 h. Typical observation heights are indicated at the top of the figure. The geomagnetic activity was relatively weak, with the AE6 index varying between 155 and 281 nT. For each profile, vertical blue lines mark the equatorward (latb) and poleward (latm) boundaries of the density drop in the equatorward trough wall. The associated densities are denoted as $N e(l a t b)=N e b$ and $N e($ latm $)=N e m$, respectively. time and longitude are determined (Sect. 3). Variations in the magnitude of the density drop with altitude, longitude, local time and magnetic activity are considered in Sect. 4. Mean latitudinal profiles of the trough wall and the associated increase in electron temperature are derived in Sect. 5. In Sect. 6, our observations are discussed and compared with previous findings. Finally, the main properties of the equatorward trough wall are summarized once more in Sect. 7.

\section{Data selection and parameterization}

The present study uses electron density and temperature measurements obtained by the Langmuir probe aboard the Dynamics Explorer (DE)-2 satellite. A general description of this satellite is given in Hoffman and Schmerling (1981), and details on the Langmuir probe experiment can be found in Krehbiel et al. (1981). Here the data contained in the unified abstract files prepared by the NASA National Space Science Data Center are analyzed.

In a first step, all DE-2 orbits were divided into four segments, each extending from equatorial to polar latitudes. In order to reduce this rather large data set, the following selection criteria were applied. First, only data obtained in the Northern Hemisphere were retained. This facilitates the identification of longitudinal variations which depend on the hemisphere considered. Second, only data obtained during winter/equinox conditions were considered. It is well known that troughs are most pronounced during these seasons. Third, only data obtained below $700 \mathrm{~km}$ altitude were retained. This eliminates all light ion troughs and leaves us with ionospheric troughs (see, e.g., Moffett and Quegan, 1983). Finally, we are only interested in the afternoon/evening sector (15:00 to 21:00 MLT) because here magnetic local time variations are expected to be most pronounced. This leaves us with 875 orbital segments.

For each of these remaining segments, the electron density was plotted as a function of invariant latitude and displayed on a terminal screen. These plots were then used to parameterize the equatorward wall of the subauroral trough. First, the latitude latb of the equatorward boundary of the density drop was estimated; see Fig. 1. The associated density value is denoted here as Neb. Second, the latitude latm of the first and most equatorward located density minimum was determined, together with the associated electron density $\mathrm{Nem}$. Note that this first density minimum may well be a secondary minimum, not necessarily well separated from other and possibly more pronounced minima at higher latitudes. As intended, this parameterization describes only the equatorward wall of the trough, not the trough as a whole. It is also clear that latm can be determined with higher precision than latb. This is especially true if the density decreases more gradually. In this case, the location of latb can be estimated only within, say, $\pm 2 \mathrm{deg}$. In an earlier study, we also tried an automated procedure to identify latb but were not satisfied with 

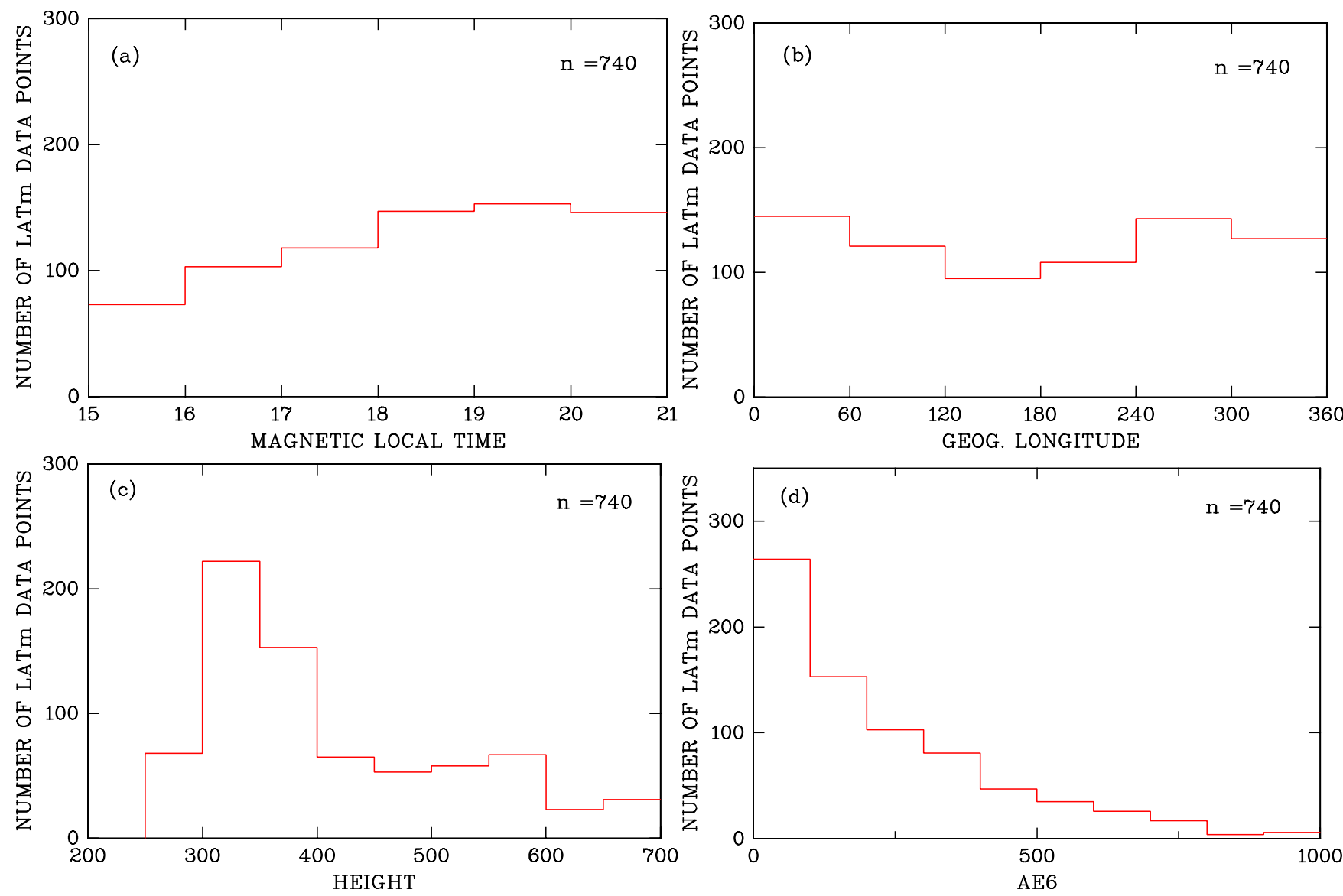

Fig. 2. Statistics of the data set analyzed in the present study. (a) Histogram indicating the magnetic local time distribution of the 740 electron density profiles parameterized. The time is given in hours. (b) Histogram indicating the geographic longitude distribution of the data set. The longitude is given in degrees east. (c) Histogram indicating the height distribution of the data set. The height is given in kilometers. (d) Histogram indicating the magnetic activity distribution of the data set. As a measure for this activity we use the $A E 6$ index defined in Eq. (1). The units of this index are nT.

the results. It appears that the pattern recognition capability of the human brain is unsurpassed. Of course, a visual identification always involves some subjective judgement, especially if the trough signatures are not well defined. It is hoped that our larger data sample will smooth out such deficiencies.

Not all density profiles allowed such a parameterization. There were quite a few cases when either no clear trough structures were detected or these trough structures could not be reliably identified in the fluctuating electron density. This happened most frequently at higher altitudes and in the longitude range $180-240^{\circ} \mathrm{E}$ where the depth of the trough is relatively small; see Sect. 4 . Also, in some cases only the minimum could be identified with sufficient accuracy. This leaves us with 740 data sets of latm and $\mathrm{Nem}$ values, and 724 data sets of all four parameters.

The statistics of our data set are presented in Fig. 2. As can be seen, the local time and longitude distributions are fairly even; see Figs. 2a and b. As to the height distribution, most data were collected in the 300 to $400 \mathrm{~km}$ altitude range (Fig. 2c). Finally, most data refer to moderately disturbed conditions; see Fig. 2d. It may also be of interest that slightly more than $70 \%$ of our data were obtained during winter conditions, and that in more than $98 \%$ of all cases the solar zenith angle was equal to or larger than 90 degrees. Solar activity during the DE-2 mission was medium to high.

\section{Location of the equatorward trough wall}

The location of the equatorward trough wall depends primarily on the level of geomagnetic activity and local time, and to a lesser degree on longitude. Here we describe and model these variations.

The latitudes of the equatorward boundary latb and first minimum latm serve as convenient parameters to specify the location of the equatorward trough wall. Selecting a suitable index to quantify the level of geomagnetic activity poses a greater problem. Various geomagnetic activity indices were tested, including the $a_{p}, K_{p}, D_{s t}, A E$, and 


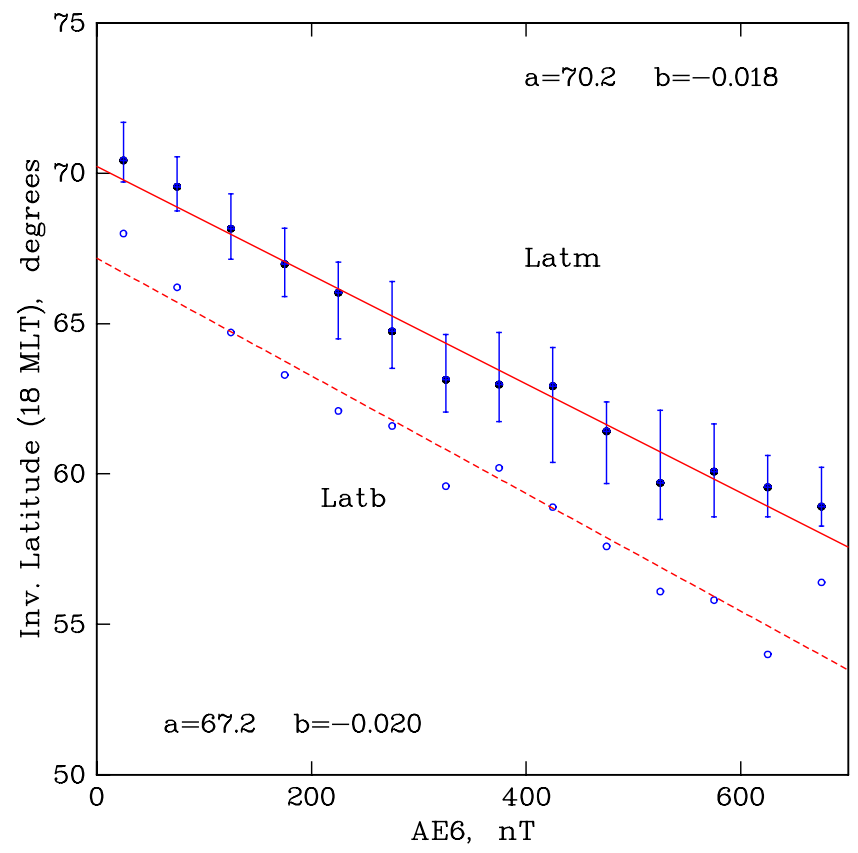

Fig. 3. Position of the equatorward trough wall as a function of geomagnetic activity. The $A E 6$ index is indicated on the abscissa, the associated invariant latitudes of the equatorward (latb) and poleward $(\mathrm{latm})$ boundaries of the trough wall on the ordinate. The median and the upper and lower quartiles of these latter parameters were determined for each $50 \mathrm{nT}$ - wide interval of the $A E 6$ index. In case of latm, these are indicated by the blue dots and bars. In the case of $l a t b$, only the respective medians are shown (open blue circles). In both cases, the quartile ranges are of comparable magnitude. Linear regression lines were fitted to the median values (latm: solid red line; latb: dashed red line). The associated ordinate intersections $a$ (in degree) and slopes $b$ (in degrees per nT) are given in the upper right-hand (latm) and lower left-hand (latb) corners, respectively. Note that the results presented in this figure refer to a magnetic local time of 18:00 h. Also note that only relatively few data points are available for $A E 6$ values larger than, say, $600 \mathrm{nT}$.

$A E 6$ indices. The best result (i.e. the highest correlation coefficient $r$ ) was obtained with the $A E 6$ index. For comparison, $r_{a p}=-0.65 ; r_{K p}=-0.75 ; r_{D s t}=0.69 ; r_{A E}=-0.69 ;$ and $r_{A E 6}=-0.83$. The $A E 6$ index was introduced by Werner and Prölss (1997) and is defined as the weighted mean of hourly averaged $A E$ indices

$$
A E 6=\frac{\sum_{i=0}^{6} A E(\mathrm{UT}-\mathrm{i}[\mathrm{h}]) e^{-i}}{\sum_{i=0}^{6} e^{-i}}
$$

Here UT refers to the universal time for which the $A E 6$ index is to be calculated (in our case the universal time of the trough observation). By not only considering the actual $A E$ index but also the $A E$ indices of the previous six hours, this index takes the "memory effect" of the ionosphere into account.

In order to find out what kind of correlation exists between the AE6 index and the location of the trough wall, all latm values were sorted into $50 \mathrm{nT}$-wide intervals of this index. For each of these intervals, the median and the upper and lower quartiles of the latm values were determined. They are indicated by the blue dots and bars in Fig. 3. As is evident, a linear correlation exists between the $A E 6$ index and the latitude of the density minimum. Therefore, a linear regression line was fitted to the median values; this is indicated by the solid red line. The associated line parameters are given in the upper right-hand corner.

According to this regression line, the inner boundary of the trough wall is located slightly poleward of $70 \mathrm{deg}$. invariant latitude, provided there is no geomagnetic activity and we are in the 18:00 $\mathrm{h}$ magnetic local time sector. For each increase in the $A E 6$ index by $100 \mathrm{nT}$, this boundary moves equatorwards by almost 2 degrees. For an $A E 6$ index of $700 \mathrm{nT}$, this results in a total displacement of almost 13 degrees.

A similar correlation study was also performed on the latitude of the equatorward boundary of the trough wall, i.e. on latb. The regression line obtained in this case is indicated by the open blue circles and the dashed red line. The associated line parameters are given in the lower left-hand corner. As can be seen, both boundaries of the trough wall move at almost the same rate towards lower latitudes with increasing geomagnetic activity. Their mean distance is about 3.5 degrees.

The location of the trough wall not only depends on the level of geomagnetic activity but also on magnetic local time. In order to describe this effect quantitatively, all latm values were sorted into $1 / 2 \mathrm{~h}$-long intervals of magnetic local time. For each of these intervals, the median and the upper and lower quartiles of the latm values were determined; see Fig. 4. Evidently, a linear correlation exists between the magnetic local time and the location of the trough wall, at least within the local time sector considered in this study. Again, a linear regression line was fitted to the median values (solid red line), and the associated line parameters are given in the upper right-hand corner.

According to this regression line, the inner boundary of the trough wall is located near $70 \mathrm{deg}$. invariant latitude at $15 \mathrm{~h}$ magnetic local time and for an $A E 6$ index of $250 \mathrm{nT}$. As time progresses, this boundary moves equatorwards by about 1.3 deg per hour. For the magnetic local time range considered in this study, this amounts to a total displacement of almost 8 degrees.

A similar correlation study was also performed on the latitude $l a t b$ of the equatorward boundary of the trough wall. The results obtained in this case are indicated by the open blue circles and the dashed red regression line. Again, latb and latm move towards lower latitudes at the same rate with progressing time. Their mean distance is about 3.5 deg., in agreement with the results of Fig. 3 .

To avoid misunderstandings, the rate at which the location of the trough wall changes with local time decreases significantly as we approach the noon or midnight sector. For example, at midnight this rate $(\approx 0.5 \mathrm{deg} . / \mathrm{h})$ is only about half 


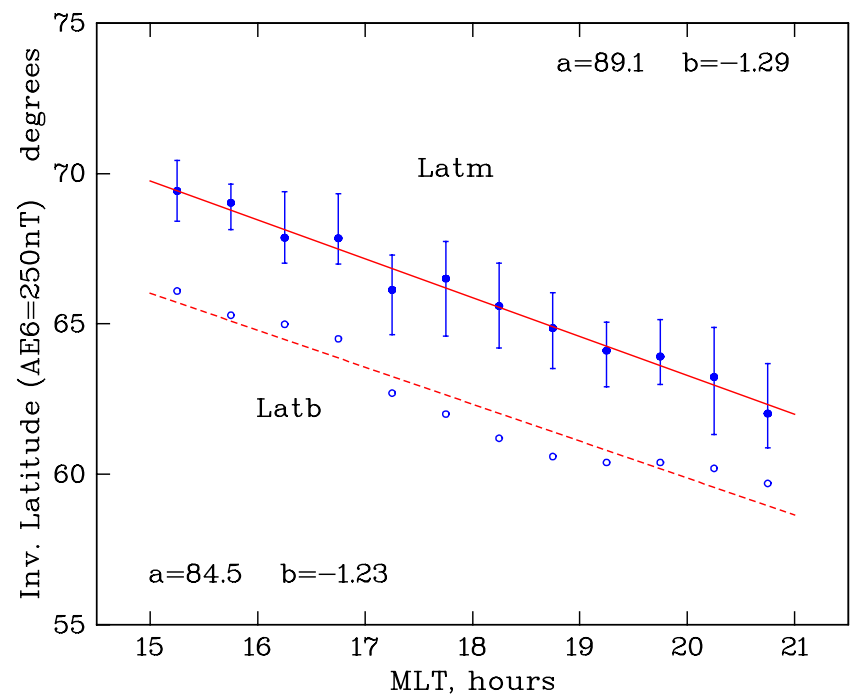

Fig. 4. Position of the equatorward trough wall as a function of magnetic local time. The format of data presentation corresponds to that of Fig. 3 except that the magnetic activity index is replaced by the magnetic local time (MLT). Note that the results presented in this figure refer to a geomagnetic activity level of $A E 6=250 \mathrm{nT}$.

the value observed in the afternoon/evening sector. Also note that the latitude values presented in Fig. 3 refer to a magnetic local time of 18:00 h. The adjustment to this common local time was accomplished with the help of the results presented in Fig. 4. Likewise, the latitude values presented in Fig. 4 refer to an $A E 6$ index of $250 \mathrm{nT}$. Their adjustment to this common level of magnetic activity was accomplished with the help of the results presented in Fig. 3. These adjustment processes were performed in an iterative fashion such that the results presented in both figures are self-consistent.

Besides depending on magnetic activity and local time, the location of the trough wall varies also with geographic longitude. This is documented in Fig. 5. The format of data presentation corresponds to that of Figs. 3 and 4 except that this time sin- and cos-functions of lowest order have been fitted to the median values. As can be seen, the amplitude of the longitudinal variation is small, and peak-to-peak changes are less than 2 degrees. For latm, poleward shifts are observed near 0 deg., and equatorward shifts near $180 \mathrm{deg}$. geographic longitude. For $l a t b$, these extrema are displaced by about $45^{\circ}$ to the west.

To summarize, the following expressions for the locations of the boundaries of the equatorward trough wall are obtained

$$
\begin{aligned}
\text { latf }= & 70.9-0.0196 \cdot A E 6-1.23 \cdot(\text { MLT }-15) \\
& -0.537 \sin \Lambda+0.589 \cos \Lambda
\end{aligned}
$$

$$
\begin{aligned}
\text { latm }= & 74.1-0.018 \cdot A E 6-1.29 \cdot(\text { MLT }-15) \\
& +0.065 \sin \Lambda+0.915 \cos \Lambda
\end{aligned}
$$

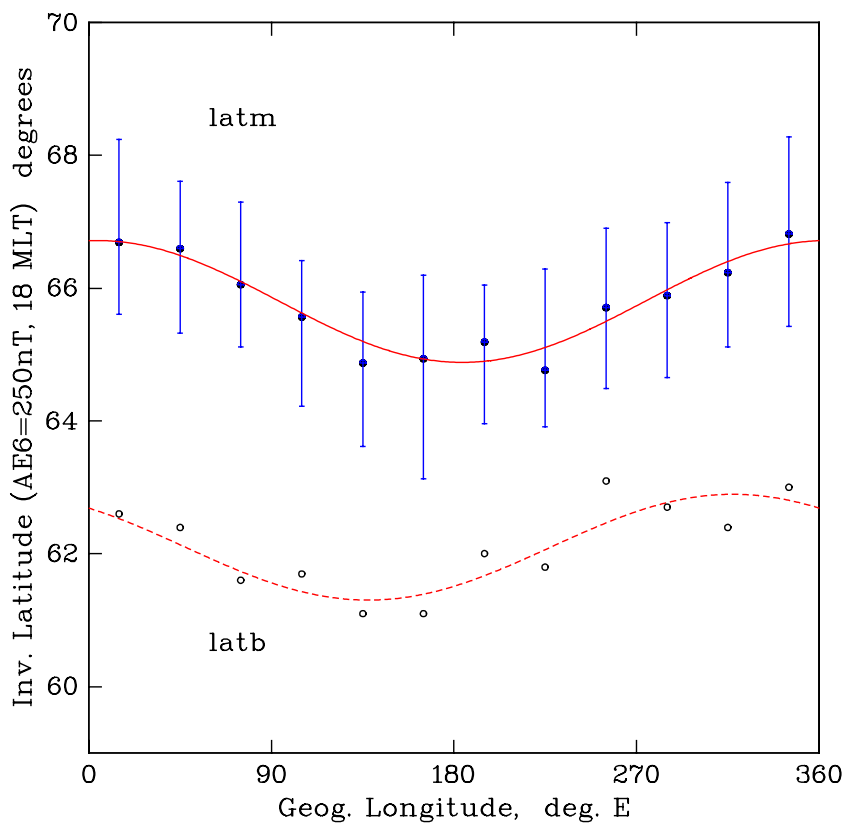

Fig. 5. Position of the equatorward trough wall as a function of geographic longitude. The format of data presentation corresponds to that of Fig. 3, except that this time the latitude range has been considerably reduced, and sin- and cos- functions have been fitted to the median values. The analytical forms of these regression curves are contained in Eqs. (2) and (3). Note that the results presented in this figure refer to a geomagnetic activity level of $A E 6=250 \mathrm{nT}$ and a magnetic local time of 18:00 h.

Here latf and latm are in degrees of invariant latitude, AE6 in $\mathrm{nT}$, the magnetic local time MLT in hours, and the geographic longitude $\Lambda$ in degrees east. Of course, these expressions only apply for the 15:00 to 21:00 h magnetic local time sector.

\section{Magnitude of the density drop in the trough wall}

Besides the location, the magnitude or depth of the density drop in the trough wall is of interest. Here the ratio of the densities observed at the equatorward and poleward boundaries of the trough wall serves as a suitable measure of this quantity

depth $=\frac{N e(\text { latb })}{N e(l a t m)}=\frac{N e b}{N e m}$

As it turns out, this parameter depends primarily on altitude and longitude.

In order to document the altitude variation, all depth values were first adjusted to a common geographic longitude of 0 deg. using the results of Fig. 7. Next, they were sorted into $20 \mathrm{~km}$-wide height intervals. For each of these intervals, the median and the upper and lower quartiles of the depth values were determined. They are indicated by the blue dots and 


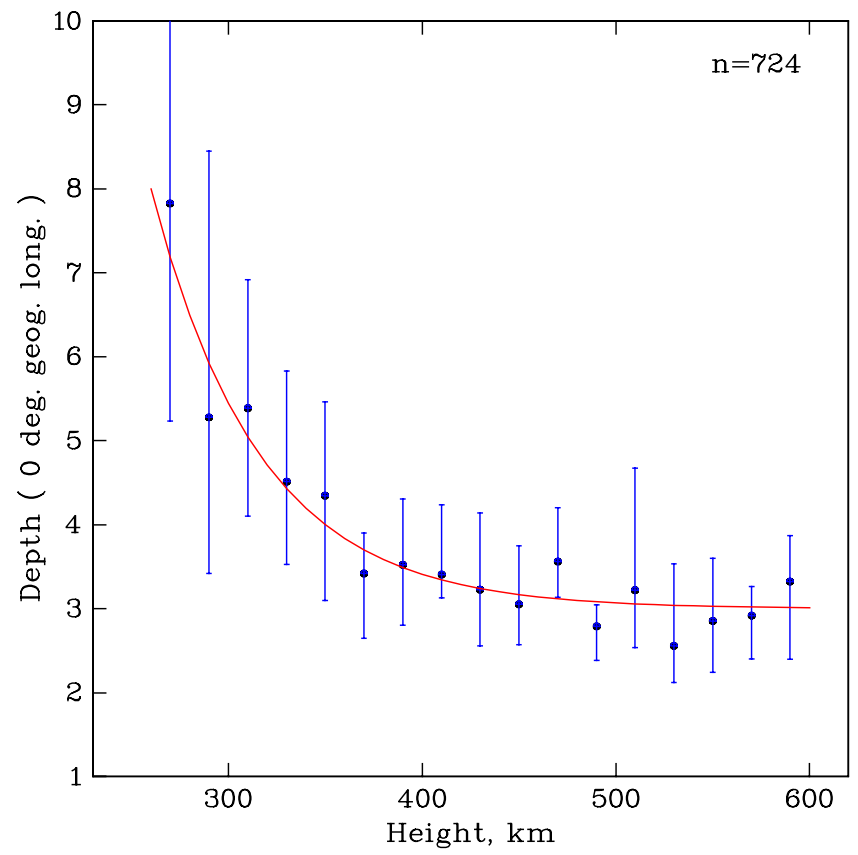

Fig. 6. Height variation of the magnitude of the density drop in the equatorward trough wall. This magnitude is denoted here as depth. It is defined as the ratio of the density values observed at the equatorward $(\mathrm{Neb})$ and poleward $(\mathrm{Nem})$ boundaries of the trough wall. For each $20 \mathrm{~km}$-wide height interval, the median and the upper and lower quartiles of this parameter were determined; see the blue dots and bars. Subsequently, the height variation of the median values was approximated by an exponential function; see Eq. (5). Note that the results presented in this figure apply to a geographic longitude of 0 degree.

bars in Fig. 6. In spite of the large scatter of the data, there is a clear trend for the magnitude of the density drop to decrease with increasing altitude. This trend is described well by the following exponential function

$\operatorname{depth}(h, 0$ deg. long. $)=3.0+5 \exp (-0.018(h-260))$

where the height $h$ is in kilometers. This approximation is indicated by the red line in Fig. 6.

In a similar way, the longitude dependence of the magnitude of the density drop is derived. In order to reduce the scatter of the data, all depth values were first adjusted to a common altitude of $350 \mathrm{~km}$ using Eq. (5). Next, they were sorted into 15 degree-wide intervals of geographic longitude. For each of these intervals, the median and the upper and lower quartiles were determined. These quantities are shown in Fig. 7. Most prominent is the strong increase in the magnitude of the density drop between about 270 and $360 \mathrm{deg}$. longitude, i.e. in the neighborhood of the magnetic north pole. An analytical description of this variation is obtained if a combination of sin- and cos-functions is fitted to the median values

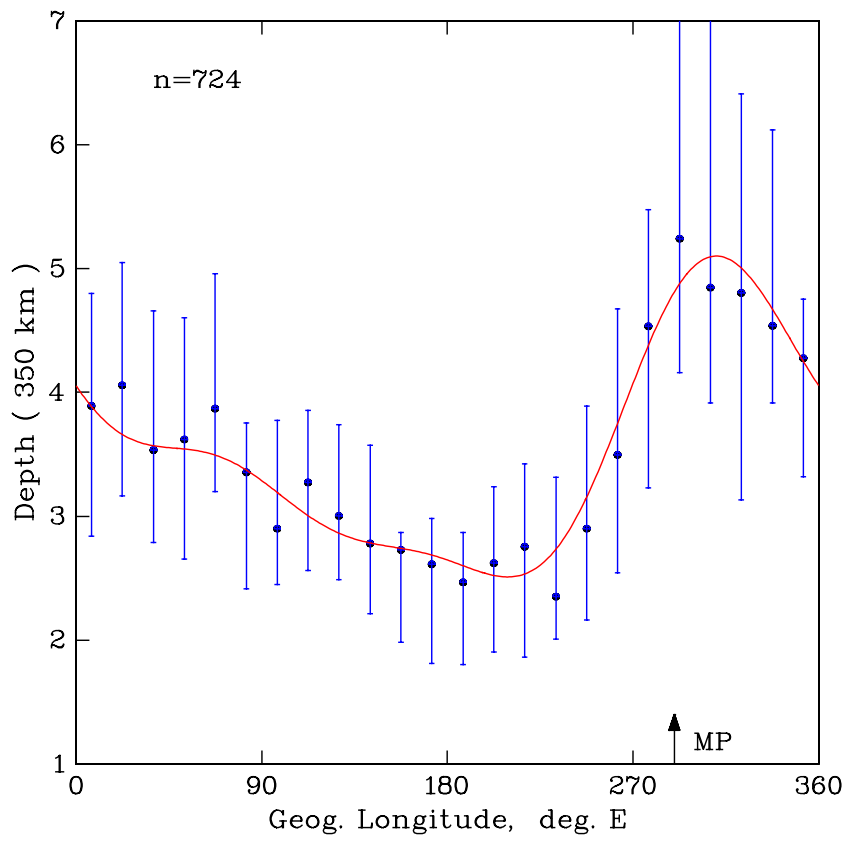

Fig. 7. Longitudinal variation of the magnitude of the density drop in the equatorward trough wall. The format of data presentation corresponds to that of Fig. 6 except that the height is replaced by the geographic longitude. The regression curve fitted to the median values is given in Eq. (6). Note that the results presented in this figure refer to an altitude of $350 \mathrm{~km}$. The approximate position of the magnetic north pole is indicated by an aroow.

$$
\begin{aligned}
\operatorname{depth}(\Lambda, 350 \mathrm{~km})= & 3.52-0.43 \sin \Lambda+0.92 \cos \Lambda \\
& -0.44 \sin (2 \Lambda)-0.17 \cos (2 \Lambda) \\
& -0.04 \sin (3 \Lambda)-0.22 \cos (3 \Lambda)
\end{aligned}
$$

see the red curve in Fig. 7. Here the longitude $\Lambda$ is in degrees east.

The depth of the density drop depends also on magnetic local time (Fig. 8) and magnetic activity (Fig. 9). These variations, however, are much less pronounced. First-order descriptions of these effects are provided by the following expressions

$$
\begin{aligned}
\text { depth }(\text { MLT, 350 km) }= & 12.19+13.08 \sin (15 \cdot \text { MLT }) \\
& +0.61 \cos (15 \cdot \text { MLT }) \\
& +0.25 \sin (30 \cdot \text { MLT }) \\
& -4.88 \cos (30 \cdot \text { MLT })
\end{aligned}
$$

$\operatorname{depth}(\mathrm{AE} 6,350 \mathrm{~km})=3.15+0.0014 \cdot A E 6$

Here the magnetic local time MLT is in hours, and the AE6 index in $\mathrm{nT}$. These approximations are indicated by the red curve and line shown in Figs. 8 and 9, respectively. 


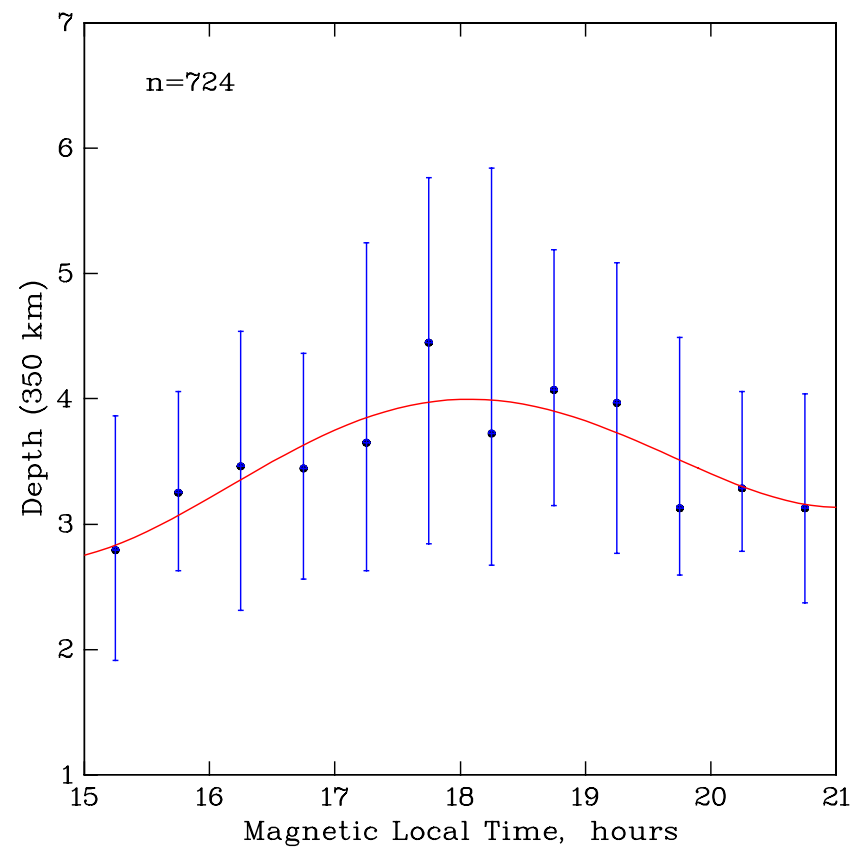

Fig. 8. Magnetic local time dependent changes in the magnitude of the density drop in the equatorward trough wall. The format of data presentation corresponds to that of Fig. 6 except that the height is replaced by the magnetic local time. The regression curve fitted to the median values is given in Eq. (7). All data have been adjusted to a common reference altitude of $350 \mathrm{~km}$.

Considering the fairly large scatter of the depth data, we refrain from summarizing the various equations in a comprehensive expression.

\section{Mean latitudinal profiles of the trough wall and the associated temperature increase}

Calculating the mean latitudinal profile of the equatorward trough wall requires special care. This is because the density drop is confined to a relatively narrow latitudinal range whose position is constantly changing with the level of geomagnetic activity. Therefore simply averaging the individual profiles would invariably smear out the density drop. To avoid this kind of distortion, a superposed epoch type of averaging procedure was used in the present study.

In a first step, all density values of a latitudinal profile were normalized. This facilitates a comparison of density profiles obtained during different geophysical conditions. Here the density value $N e b$ measured at the equatorward boundary of the trough wall serves as a suitable normalization standard. Next, all latitudinal profiles were superimposed in such a way that the density minima at latm were aligned and located at a common reference location (i.e. latm $\rightarrow$ latre $f=0$ ). This way the basic latitudinal structure of the density drop is preserved when averaging the data. Subsequently, spline func-

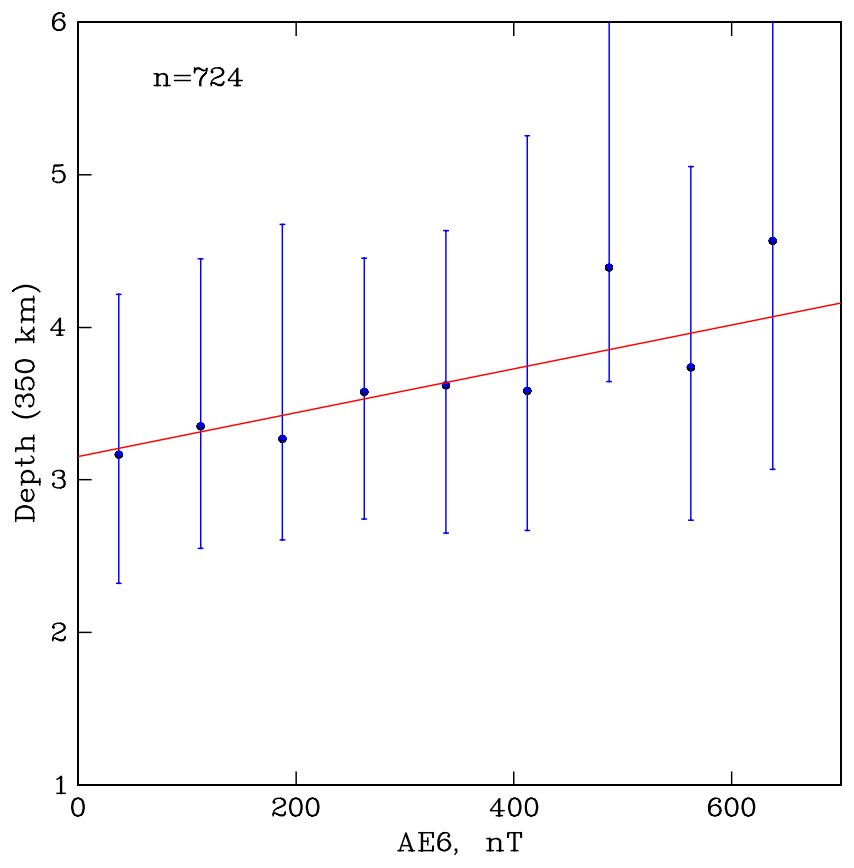

Fig. 9. Magnetic activity dependent changes in the magnitude of the density drop in the equatorward trough wall. The format of data presentation corresponds to that of Fig. 6 except that the height is replaced by the $A E 6$ index. The regression line fitted to the median values is given in Eq. (8). All data refer to a common reference altitude of $350 \mathrm{~km}$. Note that the correlation coefficient for this data set is rather low, $r=0.25$, indicating that the dependence of the trough depth on the $A E 6$ index is surprisingly weak, at least on average.

tions were fitted to each profile. This allowed us to calculate the densities at one degree steps relative to the new reference latitude. The median and the upper and lower quartiles of the density values were determined for each degree of this new coordinate system. Finally, spline functions were fitted to these parameters. The end product of this whole procedure is presented in Fig. 10.

As indicated by the shaded area between the lower and upper quartiles, the scatter of the data is quite substantial. Nevertheless, the mean electron density drop in the trough wall stands out as a relatively narrow feature, not unlike those actually observed. The decrease amounts to about $70 \%$, which at a median altitude of $372 \mathrm{~km}$ is consistent with the results presented in Fig. 6. Note that the latitudes indicated on the abscissa refer to an $A E 6$ index of $250 \mathrm{nT}$ and a magnetic local time of 18:00 h (longitudinal variations are neglected). For these conditions, the density minimum is located close to 66 deg. invariant latitude (see Fig. 3). For other levels of geomagnetic activity and/or other local times, the mean profile should be shifted towards higher or lower latitudes.

How does the electron temperature behave in the neighborhood of the density drop? To answer this question, mean latitudinal profiles of the electron temperature were generated, 


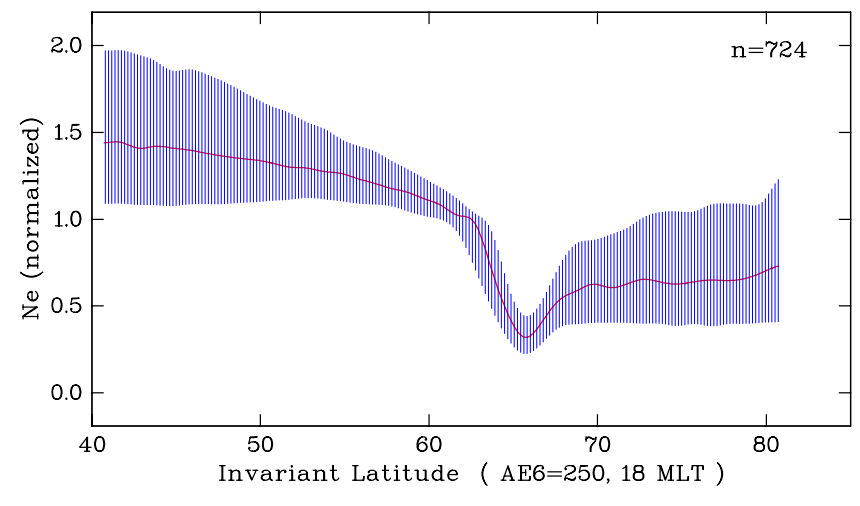

Fig. 10. Mean latitudinal profile of the equatorward trough wall. The median of 724 density profiles is plotted (red curve). These profiles have been superimposed in such a way that the latitude of the poleward boundary of the trough wall latm serves as a common reference location. In addition, all density values of a profile have been normalized to the respective density value observed at the equatorward boundary of the trough wall, Neb. The blue-shaded area indicates the range between the upper and lower quartiles. The latitudes given on the abscissa apply to a geomagnetic activity level of $A E 6=250 \mathrm{nT}$ and a magnetic local time of 18:00 h. For other conditions the mean profile should be shifted to higher or lower latitudes.

again using the latitude of the poleward boundary of the trough wall as a common reference location. The result is presented in Fig. 11. Evidently, a peak in the electron temperature is observed at the location of the density minimum. Figure 11 is the counterpart of Fig. 13 in Prölss (2006).

\section{Comparison with previous findings and discussion}

In the preceding sections, some important properties of the equatorward trough wall were described. Here our results will be discussed and compared to previous findings. Such a comparison is not straightforward since up to now there have been no other studies which specifically investigate this feature. Therefore, our results will be compared to the more general findings of previous trough studies.

\subsection{Location of the equatorward trough wall}

\subsubsection{Magnetic activity effect}

From the beginning it was realized that the trough moves towards lower latitudes with increasing geomagnetic activity (Muldrew, 1965). Since then numerous further attempts have been made to model this effect (e.g. Liszka, 1967; Thomas and Andrews, 1968; Rycroft and Thomas, 1970; Rycroft and Burnell, 1970; Tulunay and Sayers, 1971; Köhnlein and Raitt, 1977; Neske, 1978; Tulunay and Grebowsky, 1978; Collis and Häggström, 1988; Deminov et al., 1992; Karpachev et al., 1996) albeit with limited success. One

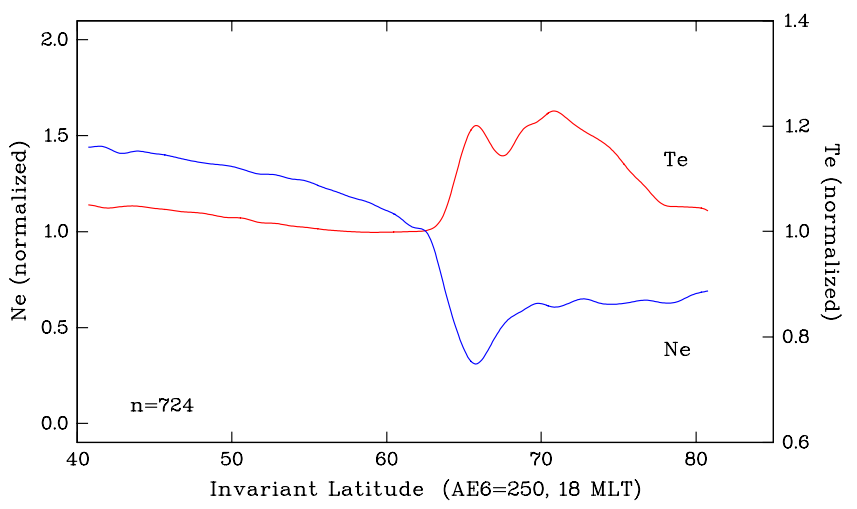

Fig. 11. Mean latitudinal profiles of the electron density (blue curve) and electron temperature (red curve) at the location of the equatorward trough wall. The format of data presentation corresponds to that of Fig. 10 except that this time only the median curves are shown.

problem here is the selection of a suitable index to specify the level of geomagnetic activity. Most of the previous studies have used the $K_{p}$ index. The big advantage of this index is that it is readily available. Disadvantages are its ill-defined physical meaning and its low time resolution, but especially its logarithmic nature which renders any summing up and/or averaging of this index a dubious procedure. Therefore, Werner and Prölss (1997, henceforth abbreviated as $\mathrm{W} \& \mathrm{P}$ ) introduced the $A E 6$ index. This index is based on the $A E$ index with its well-defined physical meaning. It also takes the history of the geomagnetic activity into account. Most importantly, this index was shown to be better correlated with the trough location than the $K_{p}$ index. Our present results support this choice. When correlating the location of the trough wall with the $K_{p}, a_{p}, D_{s t}, A E$ and $A E 6$ indices, the best correlation was obtained for the $A E 6$ index. This index was therefore also chosen in the present study to model the geomagnetic activity effect.

How does the trough minimum location modeled by W\&P compare to the trough wall location modeled in the present investigation? Since both studies are based on the DE-2 data set, similar results are to be expected. With regard to the rate at which both features move towards lower latitudes with increasing geomagnetic activity, there is indeed excellent agreement; see Fig. 12. However, the trough minimum determined in the W\&P study is displaced by about 3 deg. towards higher latitudes. This indicates that the first minimum selected in the present investigation does not always coincide with the major trough minimum selected in the W\&P study. A careful comparison of both parameterizations reveals that in simple cases like those illustrated in Fig. 1, the first minimum and the major trough minimum coincide. However, in more complex cases like those documented in Fig. 13, W\&P selected the most pronounced trough minimum, which is located at higher latitudes. This explains why the location of 


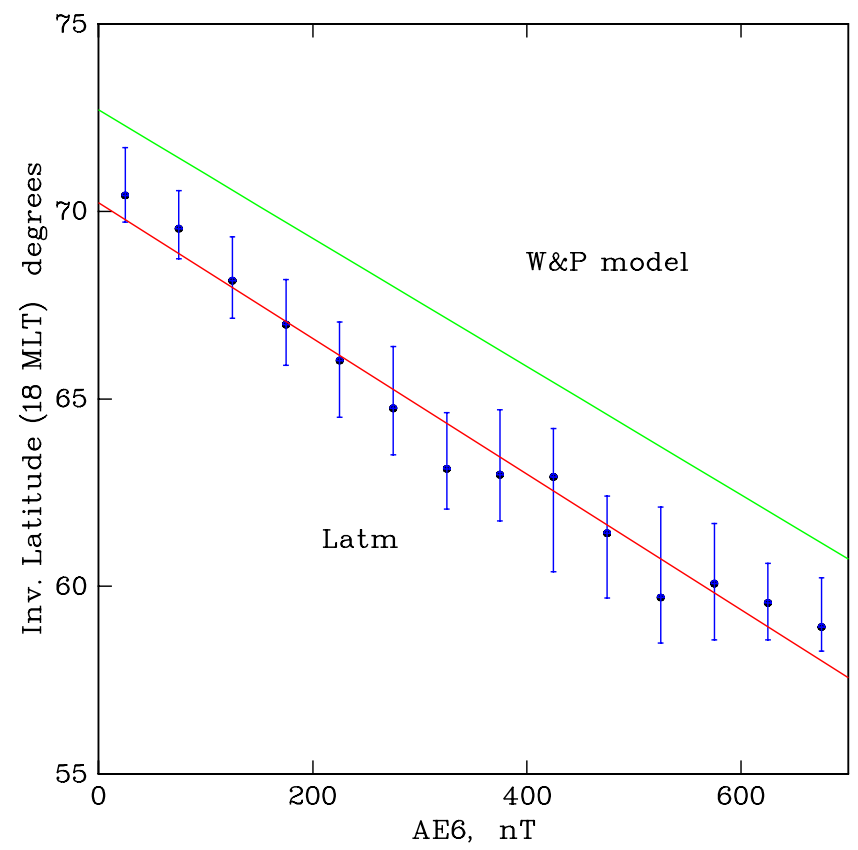

Fig. 12. Positions of the poleward boundary of the trough wall (latm, red line) and the trough minimum (green line) as a function of geomagnetic activity. The format of data presentation corresponds to that of Fig. 3. The position of the trough minimum is specified according to the model of Werner and Prölss (W\&P, 1997).

the trough minimum shown in Fig. 12 is systematically displaced towards higher latitudes.

Note in this context that more than one type of trough may exist in the daytime sector of the subauroral ionosphere (Karpachev et al., 1998). Furthermore, the results presented in Figs. 3 and 12 are only reliable in a statistical sense. If the trough wall motions observed during a geomagnetic storm are to be modeled in detail, more sophisticated algorithms are certainly needed (see, for example, Besprozvannaya and Schuka, 1994; Besprozvennaya et al., 1995; Deminov et al., 1995, 1996a, b; Annakuliev et al., 1997; Karpachev and Afonin, 2004).

\subsubsection{Local time variation}

It was also realized from the beginning that the trough location depends on local time (Muldrew, 1965). In the meantime, several attempts have been made to model this effect. Here we compare our results with those obtained by Spiro (1978), Ahmed et al. (1979), Collis and Häggström (1988), Werner and Prölss (1997), and Wielgosz et al. (2004).

As shown in Fig. 14, there is excellent agreement between the results obtained by Spiro, Collis and Häggström and the present author (op. cit.). The local time variation derived by Ahmed et al. is also in rough agreement with these results.

Larger differences are observed with respect to the Werner and Prölss (1997) study. The origin of the displacement of

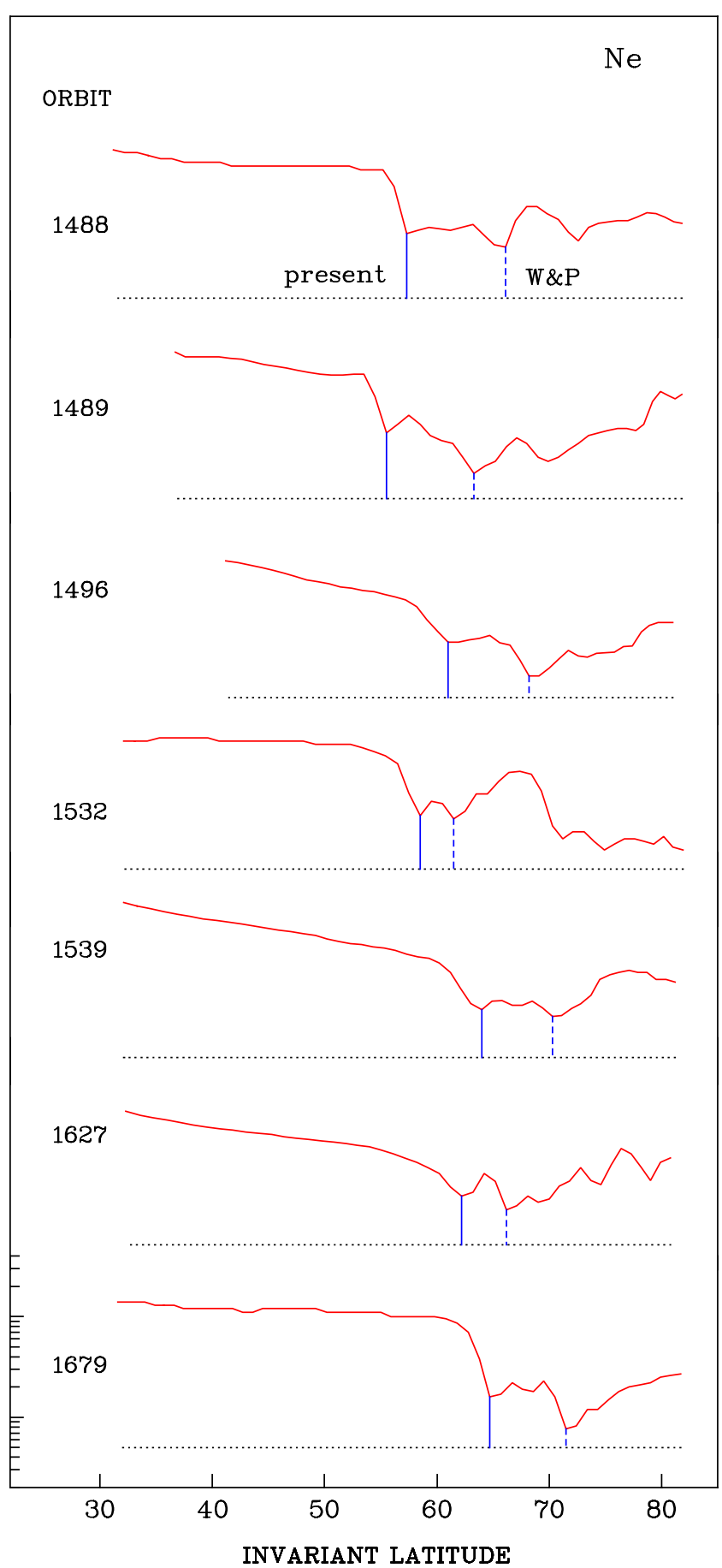

Fig. 13. Examples of more complicated trough structures. The general format of data presentation corresponds to that of Fig. 1. Shown are seven latitudinal profiles of the electron density as obtained by the DE-2 satellite between 12 November and 24 November 1981. The respective orbit numbers are given to the left of each profile. The location of the poleward boundary of the equatorward trough wall (i.e. latm) is indicated by the solid blue line. This location is compared to the position of the trough minimum (dashed blue line) as identified in the study of Werner and Prölss (W\&P, 1997). 


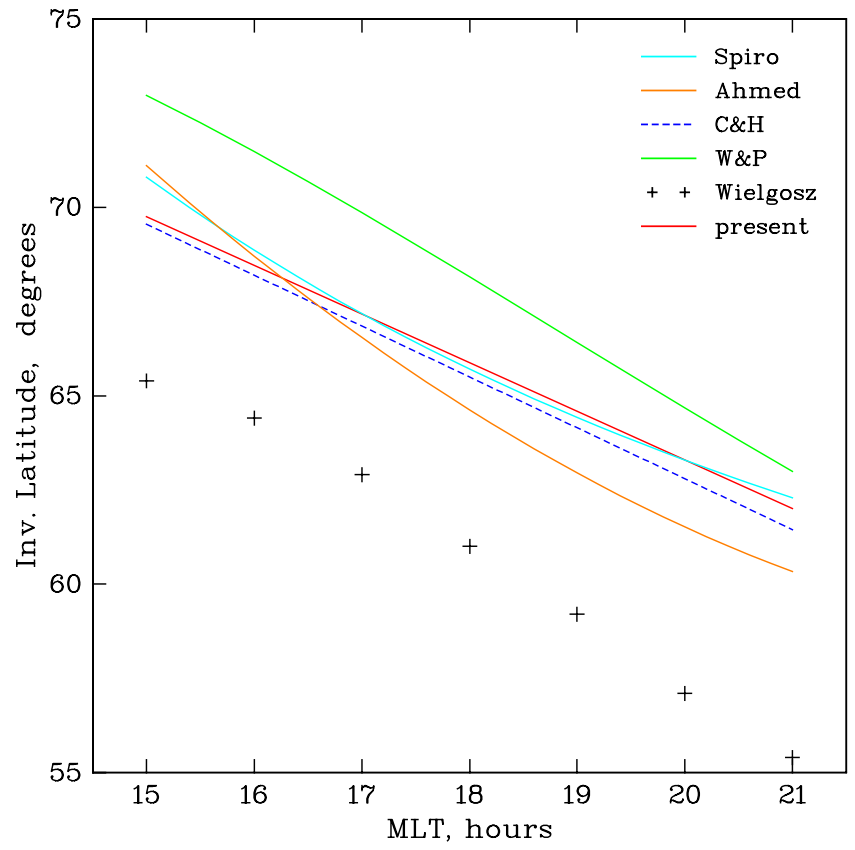

Fig. 14. Magnetic local time variation of the trough position. Results obtained by Spiro (1978; blue curve), Ahmed et al. (1979; orange curve), Collis and Häggström (C\&H, 1988; dashed cyan line), Werner and Prölss (W\&P, 1997; green curve), Wielgosz et al. (2004; crosses), and the present author (latm, red line) are compared. The format of data presentation corresponds to that of Fig. 4

the W\&P curve towards higher latitudes has already been explained. There is, however, also a slight difference in the slope of both curves. This difference may be attributed to the different data processing procedures employed. In the W\&P study the local time variation was derived without first adjusting the data to a common level of geomagnetic activity. In the present study, both the magnetic activity and local time dependence have been derived self-consistently. If the W\&P procedure is applied to the present data set, we also obtain a somewhat steeper regression line.

Whereas the slope of the local time variation derived by Wielgosz et al. (op. cit.) is not unlike those obtained in other studies, their trough location is considerably displaced towards lower latitudes. The reason for this fairly large discrepancy is not known to the author.

\subsubsection{Longitudinal variation}

More recently, the importance of longitude variations in the trough position has been emphasized (e.g. Karpachev, 1992; Deminov et al., 1992; Besprozvannaya et al., 1993; Karpachev et al., 1994, 1995; Afonin et al., 1995). In fact, initial investigations claimed the amplitude of these changes to be of the order of 10 to 11 degrees (Deminov and Karpachev, 1986a). It was also suggested that this effect depends on altitude (e.g. Afonin et al., 1992; Karpachev et al.,
1996) and local time (Karpachev and Afonin, 1999). Here we find that at least in the afternoon/evening sector, longitudinal variations are small (peak-to-peak changes less than 2 deg.) and do not depend on altitude. Figure 15 compares our results with those published by Karpachev and Afonin (1999). Evidently, the amplitude of our variation is still smaller than that derived by these latter authors. Also, the shape of our longitudinal variation agrees much better with their daytime (06:00-18:00 MLT) than with their nighttime (18:00-06:00 MLT) curve. Clearly, a reinvestigation of the longitude effect in the nighttime sector would be desirable.

\subsection{Magnitude of the density drop in the trough wall}

Compared to their location, much less is known about the shape of subauroral troughs. This has probably to do with the complexity and variability of the trough structure. A more detailed discussion of this topic can be found in Karpachev (2003).

In the simplest case, the shape of a trough is specified by its width and depth. Here we are interested in the latter parameter, especially if it is defined as the ratio of the density observed at the equatorward edge of the trough to the density observed at the trough minimum. In simple cases like those illustrated in Fig. 1, this so-defined trough depth exactly corresponds to the magnitude of the density drop in the trough wall investigated in the present study.

\subsubsection{Height variations}

The first to study the height dependence of ionospheric troughs were Mendillo and Chacko (1977). Analyzing a rather special data set referring to geomagnetically very quiet conditions in the local midnight sector of the northern winter hemisphere, they found that the trough signatures get weaker with increasing altitude. Basing their study on an even more limited data set (two Intercosmos-19 satellite passes and associated ionosonde measurements) Kozlov et al. (1988) concluded that the depth of the trough decreases with increasing height. The same conclusion was reached by Anderson et al. (1991). Comparing data obtained at different altitudes, they found that at F-region heights a deep trough appears in the ion concentration while at altitudes above about $700 \mathrm{~km}$, the trough is either absent or considerably mitigated. All these findings are consistent with our present results. Height variations of the trough depth have also been investigated by Ben'kova et al. (1992) and Karpachev (2003), but their results are less clear, and both increases and decreases with altitude are documented in their studies.

Considering that the temperature in the trough region is significantly enhanced, the decrease of the depth with altitude does not come as a surprise. Because of its larger scale height, the density inside the trough will decrease more slowly with height than outside this region. 


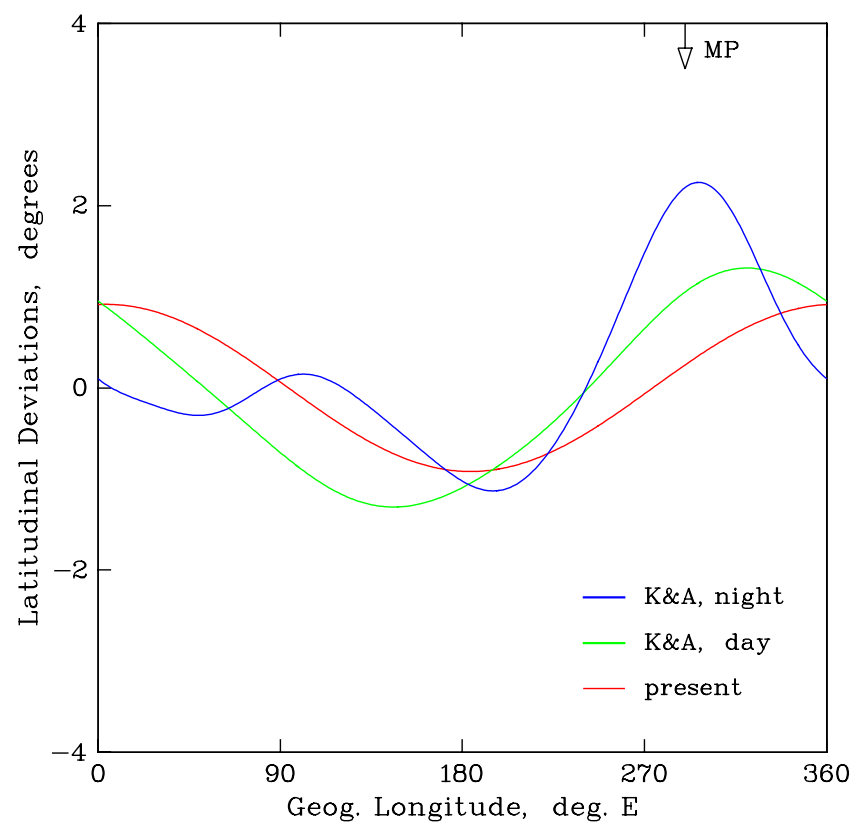

Fig. 15. Comparison of the longitudinal variation in the trough position as derived by Karpachev and Afonin (K\&A, 1999) and the present author. Plotted are deviations from the mean, with the magnetic activity and local time changes removed. The solid blue curve refers to the night sector (18:00 to 06:00 MLT), the green line to the day sector (06:00 to 18:00 MLT) of the K\&A study. Our results for latm are indicated by the red curve. The approximate position of the magnetic north pole is indicated by an arrow.

Whereas the trend documented in Fig. 6 is quite convincing, there remains the disturbingly large scatter of the data at lower altitudes. One possible explanation for this large variability is that one part of the data points refers to altitudes above, the other part to altitudes below the height of the Flayer peak. Even though troughs extend all the way from the lower to the topside ionosphere and even though the observed density profiles tend to be fairly flat (e.g. Nilsson et al., 2005), this will certainly contribute to the scatter of the data. How this affects the average height variation of the trough depth derived in the present study is difficult to say. A more detailed study of this point would require additional information on the height variation of the density within the trough wall.

\subsubsection{Longitudinal variation}

Deminov and Karpachev (1986b) were probably the first to suggest that the trough depth also depends on longitude. Subsequent work confirmed this effect (Karpachev, 1992; Besprozvannaya et al., 1993; Karpachev, 2003). A representative result of their studies is shown in Fig. 16. If their longitudinal variation is compared with ours, points of agreement and disagreement are observed. For example, the absolute maxima and minima of both curves are located at approxi-

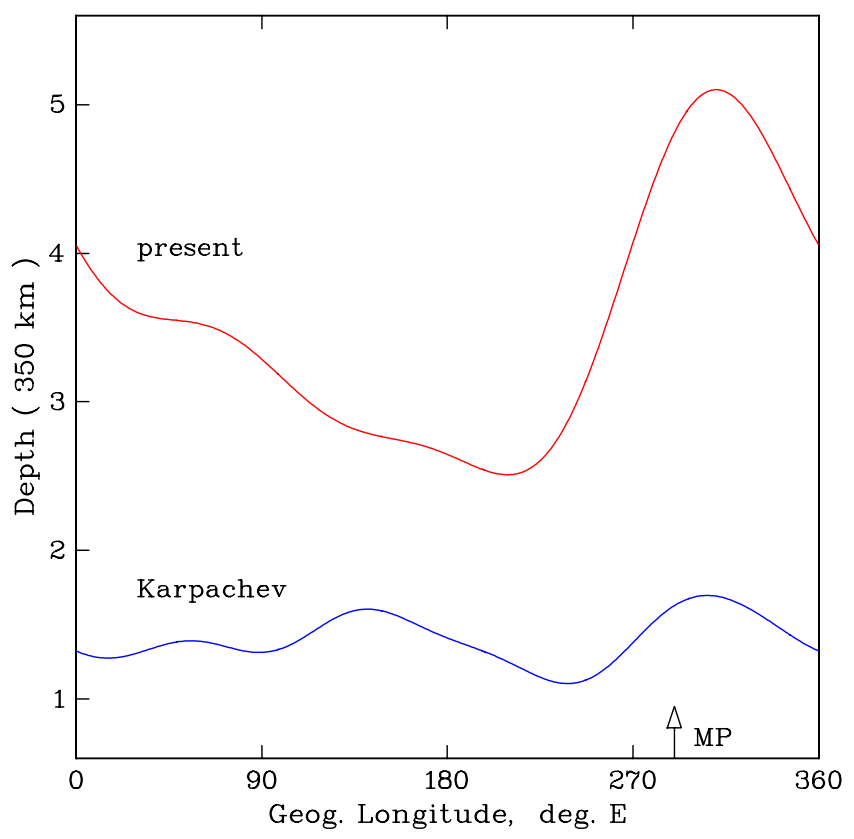

Fig. 16. Longitudinal variation in the magnitude of the density drop in the trough as derived by Karpachev (2003; blue curve) and the present author (red curve). The format of data presentation corresponds to that of Fig. 7.

mately the same longitudes, respectively. On the other hand, their secondary maximum at about $140 \mathrm{deg}$. longitude is not confirmed by our data set. Moreover, our depth values are much larger. Whether these discrepancies have to do with the different local time sectors considered or with differences in analysis techniques remains an open question. However, there can be no doubt that at least for the magnitude of the density drop in ionospheric troughs, longitudinal variations are very important.

Longitudinal variations in the trough morphology have also been identified by means of ionosonde measurements. As demonstrated by Whalen (1987, 1989), a well-defined "bite-out" is observed by all ionosonde stations located within a specific longitude sector ( 250 to $75 \mathrm{deg}$. east). This bite-out represents the leading edge of the dayside trough. According to the results presented in our Fig. 7, larger density drops $(\mathrm{Neb} / \mathrm{Nem} \geq 3.5)$ are observed between 260 and $60 \mathrm{deg}$. east, in good agreement with the bite-out region identified by Whalen. Sojka et al. (1990) have modeled this effect. They attribute it to the offset of the geomagnetic axis from the geographic axis of the Earth.

\subsubsection{Magnetic local time variation}

There has been some debate in the literature concerning the local time at which the deepest troughs are observed (e.g. Moffett and Quegan, 1983; Karpachev, 2003; and references therein). All we can contribute to this discussion is that in the 
limited local time sector considered here, the largest density drops are observed near 18:00 $\mathrm{h}$ magnetic local time.

\subsubsection{Magnetic activity effect}

Intuitively, one would expect the trough to be more pronounced during disturbed conditions, and this is indeed often observed; see the discussion in Karpachev (2003). Here we find that, on average, the magnitude of the density drop increases with increasing geomagnetic activity; see Fig. 9. However, this trend is relatively weak, and the scatter of the data is large. We are thus faced with the somewhat surprising situation that magnetic activity and local time have a much larger influence on the location than on the magnitude of the density drop in the trough wall.

\subsection{Mean latitudinal profiles}

The difficulty of deriving a mean latitudinal profile of the subauroral trough without smearing out its smaller-scale structure was first pointed out by Mendillo and Chacko (1977). Here we use a superposed epoch type of averaging procedure. This method works especially well in the neighborhood of the common reference location. We are therefore quite confident that the equatorward wall of the trough and the recovery of the density after the first minimum are well described by our mean profile.

Two possible applications of such a mean profile come into mind. First, it may be incorporated into empirical models of the ionosphere. For example, so far the International Reference Ionosphere (IRI) does not contain a specification of the subauroral trough (e.g. Bilitza, 2001). Second, such a mean profile may serve as a boundary condition for theoretical models. Especially the output of global numerical simulation studies should be compared to the mean properties of a trough (e.g. Sojka et al., 1985, 1990; Fuller-Rowell et al., 1991; Kolesnik et al., 2001; Aladjev et al., 2001; Namgaladze et al., 2003; Pryse et al., 2005; and references therein).

Our data set also offers the opportunity to look for a phenomenon which has been designated as "storm enhanced density" (Foster, 1993; Vo and Foster, 2001). By this an anomalous increase in the ionization density is meant which occurs immediately equatorward of the ionospheric trough during the initial phase of a magnetic disturbance. This feature is regularly observed at Millstone Hill at magnetic activity levels as low as $K_{p}=2$ (see also Horvath and Essex, 2003). Surprisingly, our mean profile does not show any signs of such a density enhancement. Since these density increases are thought to be especially pronounced near Millstone Hill, mean density profiles were also derived for this particular region. Again, no signs of an anomalous density increase were observed. Finally, all individual latitudinal profiles were checked with the same result. This indicates that the storm-enhanced density may not be such a common phenomenon as hitherto thought.
Recent studies on the subauroral electron temperature enhancement have raised the question as to what controls the location of this phenomenon (e.g. Kozyra et al., 1997; Liemohn et al., 2000; Prölss, 2006; Wang et al., 2006; and references therein). Is it the inner-magnetospheric heat source or is it the position of the ionospheric trough? The data presented in Fig. 11 support the latter proposition: the trough and the electron temperature enhancement are colocated, on average. Moreover, a cursory inspection of individual profiles indicates that the temperature enhancement follows the trough as it moves back and forth in response to changes in geomagnetic activity and local time. There are, however, also cases when additional temperature enhancements are observed at middle latitudes and well equatorward of the trough. These heating effects may well be associated with the magnetospheric ring current.

Following Sharp (1966), ionospheric troughs are frequently designated as "mid-latitude" troughs implying that middle latitudes extend all the way to the auroral oval. Here we prefer to call them "subauroral" troughs and consider subauroral latitudes a separate region. Among others, this region is characterized by anomalous changes in the density, temperature and ion drift (i.e. the subauroral trough, the subauroral temperature enhancement and the subauroral polarization stream). Projected into the magnetosphere, subauroral latitudes correspond to the plasmasphere-plasmasheet transition region which also contains the plasmaspheric boundary layer and the plasmapause (e.g. Lemaire and Gringauz, 1998; Yizengaw et al., 2005; Yizengaw and Moldwin, 2005; and references therein). Considering subauroral latitudes a separate region also implies that subauroral phenomena like the equatorward trough wall may be used to define the poleward boundary of the mid-latitude region.

\section{Summary of observations}

This study investigates the sudden density drop in the equatorward wall of the subauroral trough. For the afternoon/evening sector in the shadow region of the Northern Hemisphere, the properties of this remarkable feature may be summarized as follows.

- The mean width of the trough wall is 3.5 degrees. Within this latitude range, the density decreases by a factor of 0.32 , on average.

- The location of the trough wall depends primarily on the level of geomagnetic activity and magnetic local time. Other variations, like changes with longitude, are of secondary importance.

- The location of the trough wall correlates best with the geomagnetic activity index $A E 6$, defined in Eq. (1). For each increase of this index by $100 \mathrm{nT}$, the trough boundary moves towards lower latitudes by about 2 degrees. 
- Within the local time sector considered (15:00 to 21:00 $\mathrm{h}$ magnetic local time), the trough wall moves towards lower latitudes at a rate of $1.3 \mathrm{deg}$. per hour.

- The magnitude of the density drop in the trough wall depends primarily on altitude and longitude. Other variations, like changes with local time and the level of geomagnetic activity, are of secondary importance.

- Within the height range considered (ca. 250 to $700 \mathrm{~km}$ ), the magnitude of the density drop in the trough wall decreases exponentially with increasing altitude.

- Longitudinal variations are more complex, with the largest density drops observed between about 100 deg. west and $60 \mathrm{deg}$. east, i.e. in the neighborhood of the magnetic north pole.

- No signs of an anomalous increase in the density at the equatorward edge of the trough are observed.

- On average, the electron temperature increases as the density decreases in the trough wall. This indicates that the location of the subauroral electron temperature enhancement is primarily controlled by the position of the subauroral trough.

Since the afternoon/evening sector in the shadow region of the Northern Hemisphere is certainly not the only place where subauroral troughs are observed, our present investigation should be considered a pilot study. Future investigations should extend our study and establish the properties of the equatorward trough wall for all local time sectors, for all solar zenith angles, and for both hemispheres.

Acknowledgements. The DE-2 data used in this study were kindly provided by the NASA National Space Science Data Center. I am grateful to all the experimenters who contributed to this data set. I am also indebted to S. Werner for helpful discussions. Finally, I would like to thank M. Hanussek and K. Schrüfer for their help in preparing this manuscript.

Topical Editor M. Pinnock thanks A. Rodger and another referee for their help in evaluating this paper.

\section{References}

Afonin, V. V., Deminov, M. G., Karpachev, A. T., Ben'kova, N. P., Besprozvannaya, A. S., Shestakova, L. V., Smilauer, Ya., and Schuka, T. I.: Longitudinal variations in the position of the main ionospheric trough for nighttime winter conditions based on Kosmos-900 and Interkosmos-19 satellite data, Geomag. Aeron., 32, 217-220, 1992.

Afonin, V. V., Benkova, N. P., Besprozvannaya, A. S., Schuka, T. I., Zikrach, E. K., and Shestakova, L. V.: The ionospheric trough dynamics in the northern and southern hemispheres: the longitudinal and IMF effect, J. Atmos. Terr. Phys., 57, 1057-1062, 1995.
Afonin, V. V., Bassolo, V. S., Smilauer, J., and Lemaire, J. F.: Motion and erosion of the nightside plasmapause region and of the associated subauroral electron temperature enhancement: Cosmos 900 observations, J. Geophys. Res., 102, 2093-2103, 1997.

Afraimovich, E. L., Lesyuta, O. S., Perevalova, N. P., Pirog, O. M., Smirnov, V. F., Zirkach, E. K., and Bondar, E. D.: Study of the main ionospheric trough based on data of the GPS and ionospheric stations in the Yakutsk region, Geomag. Aeron., 45, 203-208, 2005.

Ahmed, M., Sagalyn, R. C., Wildman, P. J. L., and Burke, W. J.: Topside ionospheric trough morphology: Occurrence frequency and diurnal, seasonal, and altitude variations, J. Geophys. Res., 84, 489-498, 1979.

Aladjev, G. A., Evstafiev, O. V., Mingalev, V. S., Mingaleva, G. I., Tereshchenko, E. D., and Khudukon, B. Z.: Interpretation of ionospheric F-region structures in the vicinity of ionisation troughs observed by satellite radio tomography, Ann. Geophys., 19, 25-36, 2001, http://www.ann-geophys.net/19/25/2001/.

Anderson, P. C., Heelis, R. A., and Hanson, W. B.: The ionospheric signatures of rapid subauroral ion drifts, J. Geophys. Res., 96, 5785-5792, 1991.

Annakuliev, S. K., Afonin, V. V., Deminov, M. G., and Karpachev, A. T.: An empirical formula for the position of the main ionospheric trough during a magnetic storm, Geomag. Aeron., 37, 392-395, 1997.

Ben'kova, N. P., Kozlov, Ye. F., Kochenova, N. A., Samorokin, N. I., and Fligel, M. D.: The altitude structure of the main ionospheric trough based on satellite data, Geomag. Aeron., 32, 221224, 1992.

Besprozvannaya, A. S. and Schuka, T. I.: Dynamics of the main ionospheric trough during magnetic storms with a developed ring current, Geomag. Aeron., 33, 825-829, 1994.

Besprozvannaya, A. S., Dachev, Ts., Kilifarska, N., and Schuka, T. I.: Longitudinal effect on the shape of the main ionospheric trough in the disturbed period of 20-25 October 1981, J. Atmos. Terr. Phys., 55, 93-98, 1993.

Besprozvannaya, A. S., Schuka, T. I., Nepomnyashchaya, E. V., Kishcha, P. V., and Pulinets, S. A.: Influence of DR current on the ionospheric trough dynamics during the magnetic storms of September 1989, Geomag. Aeron., 34, 569-572, 1995.

Bilitza, D.: International Reference Ionosphere 2000, Radio Sci., 36, 261-275, 2001.

Collis, P. N. and Häggström, I.: Plasma convection and auroral precipitation processes associated with the main ionospheric trough at high latitudes, J. Atmos. Terr. Phys., 50, 389-404, 1988.

Deminov, M. G. and Karpachev, A. T.: Longitude effect in the configuration of the main ionospheric trough. I. Position of the trough, Geomag. Aeron., 26, 48-52, 1986a.

Deminov, M. G. and Karpachev, A. T.: Longitudinal effect in the configuration of the main ionospheric trough. II. Shape of the trough, Geomag. Aeron., 26, 574-575, 1986b.

Deminov, M. G., Karpachev, A. T., Afonin, V. V., and Smilauer, Ya.: The changes in position of the main ionosphere trough as a function of longitude and geomagnetic activity, Geomag. Aeron., 32, 735-738, 1992.

Deminov, M. G., Karpachev, A. T., Afonin, V. V., Annakuliev, S. K., and Smilauer, Ya.: Dynamics of midlatitude ionospheric trough during storms 1. A qualitative picture, Geomag. Aeron., 35, 54- 
59, 1995.

Deminov, M. G., Karpachev, A. T., Annakuliev, S. K., Afonin, V. V., and Smilauer, Ya.: Dynamics of the ionization troughs in the night-time subauroral F-region during geomagnetic storms, Adv. Space Res., 17(10), 141-145, 1996a.

Deminov, M. G., Karpachev, A. T., Afonin, V. V., and Annakuliev, S. K.: Dynamics of a midlatitude ionospheric trough in the recovery phase of a magnetic storm, Geomag. Aeron., 36, 452-457, 1996b.

Foster, J. C.: Storm time plasma transport at middle and high latitudes, J. Geophys. Res., 98, 1675-1689, 1993.

Fuller-Rowell, T. J., Rees, D., Quegan, S., and Moffett, R. J.: Numerical simulations of the sub-auroral F-region trough, J. Atmos. Terr. Phys., 53, 529-540, 1991.

Hargreaves, J. K. and Burns, C. J.: Electron content measurements in the auroral zone using GPS: preliminary observations of the main trough and a survey of the degree of irregularity in summer, J. Atmos. Terr. Phys., 58, 1449-1457, 1996.

Hoffman, R. A. and Schmerling, E. R.: Dynamics Explorer program: An overview, Space Sci. Instr., 5, 345-348, 1981.

Horvath, I. and Essex, E. A.: The southern-hemisphere mid-latitude day-time and night-time trough at low-sunspot numbers, J. Atmos. Solar-Terr. Phys., 65, 917-940, 2003.

Karpachev, A. T.: Global variations of $f_{0} F_{2}$ in the night trough region, Geomag. Aeron., 32, 665-668, 1992.

Karpachev, A. T.: The dependence of the main ionospheric trough shape on longitude, altitude, season, local time, and solar and magnetic activity, Geomag. Aeron., 43, 239-251, 2003.

Karpachev, A. T. and Afonin, V. V.: Longitudinal variations in the positions of daytime winter ionospheric troughs, Geomag. Aeron., 39, 194-200, 1999.

Karpachev, A. T. and Afonin, V. V.: Variations in the structure of the high-latitude ionosphere during the March 22-23, 1979, storm based on Cosmos-900 and Intercosmos-19 data, Geomag. Aeron., 44, 60-68, 2004.

Karpachev, A. T., Afonin, V. V., and Smilauer, Ya.: Variations of the nighttime trough position with longitude in winter and equinox conditions: A comparison, Geomag. Aeron., 55-59, 5559, 1994.

Karpachev, A. T., Deminova, G. F., and Pulinets, S. A.: Ionospheric changes in response to IMF variations, J. Atmos. Terr. Phys., 57, 1415-1432, 1995.

Karpachev, A. T., Deminov, M. G., and Afonin, V. V.: Model of the mid-latitude ionospheric trough on the base of Cosmos-900 and Intercosmos-19 satellites data, Adv. Space Res., 18(6), 221-230, 1996.

Karpachev, A. T., Deminov, M. G., and Afonin, V. V.: Two branches of day-time winter ionospheric trough according to Cosmos-900 data at F2-layer heights, Adv. Space Res., 22(6), 877-882, 1998.

Kersley, L., Pryse, S. E., Walker, I. K., Heaton, J. A. T., Mitchell, C. N., Williams, M. J., and Willson, C. A.: Imaging of electron density troughs by tomographic techniques, Radio Sci., 32, 1607-1621, 1997.

Köhnlein, W. and Raitt, W. J.: Position of the mid-latitude trough in the topside ionosphere as deduced from Esro 4 observations, Planet. Space Sci., 25, 600-602, 1977.

Kolesnik, A. G., Chernyshev, V. I., and Belov, M. V.: Some specific features of the spatiotemporal behavior of the main ionospheric trough, Geomag. Aeron., 41, 330-334, 2001.
Kozlov, Ye. F., Samorokin, N. I., Ben'kova, N. P., and Kochenova, N. A.: The main ionosphere dip during a substorm, Geomag. Aeron., 28, 745-747, 1988.

Kozyra, J. U., Nagy, A. F., and Slater, D. W.: High-altitude energy source(s) for stable auroral red arcs, Rev. Geophys., 35, 155-190, 1997.

Krehbiel, J. P., Brace, L. H., Theis, R. F., Pinkus, W. H., and Kaplan, R. B.: The Dynamics Explorer Langmuir probe instrument, Space Sci. Instr., 5, 493-502, 1981.

Lemaire, J. E., and Gringauz, K. I.: The Earth's Plasmasphere, Cambridge University Press, Cambridge/UK, 1998.

Liemohn, M. W., Kozyra, J. U., Richards, P. G., Khazanov, G. V., Buonsanto, M. J., and Jordanova, V. K.: Ring current heating of the thermal electrons at solar maximum, J. Geophys. Res., 105, 27 767-27 776, 2000.

Liszka, L.: The high-latitude trough in ionospheric electron content, J. Atmos. Terr. Phys., 29, 1243-1259, 1967.

Mallis, M. and Essex, E. A.: Diurnal and seasonal variability of the southern-hemisphere main ionospheric trough from differentialphase measurements, J. Atmos. Terr. Phys., 55, 1021-1037, 1993.

Meggs, R. W., Mitchell, C. N., and Howells, V. S. C.: Simultaneous observations of the main trough using GPS imaging and the EISCAT radar, Ann. Geophys., 23, 753-757, 2005, http://www.ann-geophys.net/23/753/2005/.

Mendillo, M. and Chacko, C. C.: The baselevel ionospheric trough, J. Geophys. Res., 82, 5129-5137, 1977.

Moffett, R. J. and Quegan, S.: The mid-latitude trough in the electron concentration of the ionospheric F-layer: a review of observations and modelling, J. Atmos. Terr. Phys., 45, 315-343, 1983.

Muldrew, D. B.: F-layer ionization troughs deduced from Alouette data, J. Geophys. Res., 70, 2635-2650, 1965.

Namgaladze, A. N., Evstafiev, O. V., Khudukon, B. Z., and Namgaladze, A. A.: Model interpretation of the ionospheric F-region electron density structures observed by ground-based satellite tomography at sub-auroral and auroral latitudes in Russia in January-May 1999, Ann. Geophys., 21, 1005-1016, 2003, http://www.ann-geophys.net/21/1005/2003/.

Neske, E.: High latitude structures in ionospheric plasma, Space Res., 8, 237-240, 1978.

Nilsson, H., Sergienko, T. I., Ebihara, Y., and Yamauchi, M.: Quiettime mid-latitude trough: influence of convection, field-aligned currents and proton precipitation, Ann. Geophys., 23, 32773288, 2005, http://www.ann-geophys.net/23/3277/2005/.

Prölss, G. W.: Subauroral electron temperature enhancement in the nighttime ionosphere, Ann. Geophys., 24, 1871-1885, 2006, http://www.ann-geophys.net/24/1871/2006/.

Pryse, S. E., Kersley, L., Williams, M. J., and Walker, I. K.: The spatial structure of the dayside ionospheric trough, Ann. Geophys., 16, 1169-1179, 1998, http://www.ann-geophys.net/16/1169/1998/.

Pryse, S. E., Dewis, K. L., Balthazor, R. L., Middleton, H. R., and Denton, M. H.: The dayside high-latitude trough under quiet geomagnetic conditions: Radio tomography and the CTIP model, Ann. Geophys., 23, 1199-1206, 2005, http://www.ann-geophys.net/23/1199/2005/.

Rodger, A. S., Brace, L. H., Hoegy, W. R., and Winningham, J. D.: The poleward edge of the mid-latitude trough - its formation, 
orientation and dynamics, J. Atmos. Terr. Phys., 48, 715-728, 1986.

Rodger, A. S., Moffett, R. J., and Quegan, S.: The role of ion drift in the formation of ionisation troughs in the mid- and high-latitude ionosphere - a review, J. Atmos. Terr. Phys., 54, 1-30, 1992.

Rycroft, M. J. and Burnell, S. J.: Statistical analysis of movements of the ionospheric trough and the plasmapause, J. Geophys. Res., 75, 5600-5604, 1970.

Rycroft, M. J. and Thomas, J. O.: The magnetospheric plasmapause and the electron density trough at the Alouette I orbit, Planet. Space Sci., 18, 65-80, 1970.

Sharp, G. W.: Midlatitude trough in the night ionosphere, J. Geophys. Res., 71, 1345-1356, 1966.

Shestakova, L. V., Afonin, V. V., Khalipov, V. L., Stepanov, A. E., and Zikrach, E. K.: Specific features of the high-latitude ionosphere in noon hours during the disturbance of August 29, 1979, Geomag. Aeron., 38, 396-399, 1998.

Sojka, J. J., Raitt, W. J., Schunk, R. W., Parish, J. L., and Rich, F. J.: Diurnal variation of the dayside, ionospheric, mid-latitude trough in the southern hemisphere at $800 \mathrm{~km}$ : Model and measurement comparison, Planet. Space Sci., 33, 1375-1382, 1985.

Sojka, J. J., Schunk, R. W., and Whalen, J. A.: The longitude dependence of the dayside $F$ region trough: A detailed modelobservation comparison, J. Geophys. Res., 95, 15 275-15 280, 1990.

Spiro, R. W.: PhD thesis, Univ. Texas at Dallas, Richardson, Tx, as published in Fig. 10 of Moffett and Quegan (1983), 1978.

Thomas, J. O. and Andrews, M. K.: Transpolar exospheric plasma: 1. Plasmasphere termination, J. Geophys. Res., 73, 7407-7417, 1968.

Tulunay, Y. K. and Sayers, J.: Characteristics of the mid-latitude trough as determined by the electron density experiment on Ariel III, J. Atmos. Terr. Phys., 33, 1737-1761, 1971.

Tulunay, Y. K. and Grebowsky, J. M.: The noon and mid-latitude trough as seen by Ariel 4, J. Atmos. Terr. Phys., 40, 845-855, 1978.
Vo, H. B. and Foster, J. C.: A quantitative study of ionospheric density gradients at midlatitudes, J. Geophys. Res., 106, $21555-$ $21563,2001$.

Voiculescu, M., Virtanen, I., and Nygrén, T.: The F-region trough: seasonal morphology and relation to interplanetary magnetic field, Ann. Geophys., 24, 173-185, 2006, http://www.ann-geophys.net/24/173/2006/.

Wang, W., Burns, A. G., and Killeen, T. L.: A numerical study of the response of ionospheric electron temperature to geomagnetic activity, J. Geophys. Res., 111, A11301, doi:10.1029/2006JA011698, 2006.

Werner, S. and Prölss, G. W.: The position of the ionospheric trough as a function of local time and magnetic activity, Adv. Space Res., 20(9), 1717-1722, 1997.

Whalen, J. A.: Daytime F layer trough observed on a macroscopic scale, J. Geophys. Res., 92, 2571-2576, 1987.

Whalen, J. A.: The daytime F layer trough and its relation to ionospheric-magnetospheric convection, J. Geophys. Res., 94, 17 169-17 184, 1989.

Wielgosz, P., Baran, L. W., Shagimuratov, I. I., and Aleshnikova, M. V.: Latitudinal variations of TEC over Europe obtained from GPS observations, Ann. Geophys., 22, 405-415, 2004, http://www.ann-geophys.net/22/405/2004/.

Yizengaw, E. and Moldwin, M. B.: The altide extension of the midlatitude trough and its correlation with the plasmapause motion, Geophys. Res. Lett., 32, L09105, doi:10.1029/2005GL022854, 2005.

Yizengaw, E., Wei, H., Moldwin, M. B., Galvan, D., Mandrake, L., Mannucci, A., and Pi, X.: The correlation between mid-latitude trough and the plasmapause, Geophys. Res. Lett., 32, L10102, doi:10.1029/2005GL022954, 2005.

Zikrach, E. K., Shestakova, L. V., Stepanov, A. E., Khalipov, V. L., Plotnikov, I. Ya., and Afonin, V. V.: Effect of asymmetry in variations of plasma density and temperature at latitudes of the main ionospheric trough in conjugate hemispheres, Geomag. Aeron., 39, 512-514, 1999. 